\title{
Equação de Predição da Exigência de Proteína Bruta para Aves Reprodutoras Pesadas na Fase de Produção ${ }^{1}$
}

\author{
Carlos Bôa-Viagem Rabello², Nilva Kazue Sakomura ${ }^{3}$, Flavio Alves Longo ${ }^{4}$, \\ Kleber Tomaz de Resende ${ }^{3}$, Humberto Pena Couto ${ }^{5}$
}

\begin{abstract}
RESUMO - O objetivo do presente trabalho foi determinar as exigências de proteína para aves reprodutoras pesadas através do método fatorial. A exigência de proteína bruta para mantença $(\mathrm{PBm})$ foi determinada por intermédio da técnica do balanço de nitrogênio por meio de ensaio de metabolismo com aves submetidas a quatro dietas com níveis decrescentes de proteína, proporcionando balanço positivo, próximo a zero e negativo. Para determinar a exigência de proteína bruta para o ganho de peso (PBg) dois experimentos foram conduzidos, sendo que em um, determinou-se as exigências líquidas de nitrogênio e no outro, a eficiência de utilização do nitrogênio para o ganho, por meio de abates semanais de aves no período de 26 a 33 semanas de idade. A exigência de proteína bruta para produção de ovos (PBo) foi determinada através de análises semanais de proteína bruta dos ovos coletados, no período de 31 a 37 semanas de idade, considerando a eficiência de deposição da proteína no ovo. A exigência e eficiência de utilização da proteína para mantença foram 2.282 $\mathrm{mg} \mathrm{PB} / \mathrm{kg}^{0,75} /$ dia e 60,79\%; respectivamente. As exigências de PBg e PBo determinadas foram: $356 \mathrm{mg} \mathrm{PB/g} \mathrm{e} 262 \mathrm{mg} \mathrm{PB} / \mathrm{g}$, respectivamente, e as eficiências de utilização do nitrogênio, 40 e 46,80\%, respectivamente. A equação de predição elaborada para aves reprodutoras pesadas na fase de produção foi: $\mathrm{PB}=2,282 . \mathrm{P}^{0,75}+0,356 . \mathrm{G}+0,262 . \mathrm{MO}$, onde $\mathrm{PB}$ é a exigência de proteína bruta ( $\mathrm{g} / \mathrm{ave} / \mathrm{dia}$ ), P o peso corporal (kg), G o ganho de peso (g/dia) e MO a massa de ovos (g/dia).
\end{abstract}

Palavras-chave: balanço de nitrogênio, equação de predição, exigência de proteína, método fatorial, reprodutoras pesadas

\section{Prediction Equation of Crude Protein Requirements for Broiler Breeders Hens}

\begin{abstract}
The objective of this study was to determine the protein requirement for broiler breeder hens using factorial method. The requirement of crude protein for maintenance $(\mathrm{CPm})$ was determined using nitrogen balance technique in metabolism assay. The birds were fed with four protein levels in order to get a positive, a close to zero and a negative nitrogen balance. To determine the crude protein weight gain requirement $(\mathrm{CPg})$, two experiments were carried out. The first was calculate to determine the net nitrogen requirement and the other to determine nitrogen use efficiency for body deposition, from 26 to 33 weeks old. The crude protein requirement for egg production $(\mathrm{CPe})$ was determined by content of crude protein of eggs measured in birds from 31 to 37 weeks old. The protein requirement for maintenance was $2,282 \mathrm{mg} \mathrm{CP} / \mathrm{kg}^{0.75} /$ day and the protein efficiency $60.79 \%$. The nitrogen requirement for weight gain and egg production were: $356 \mathrm{mgCP} / \mathrm{g}$ and $262 \mathrm{mg}$ of $\mathrm{CP} / \mathrm{g}$, respectively, and the protein efficiency utilization were: 40 and $46.80 \%$ for weight gain and egg production, respectively. The prediction equation for broiler breeder hens was : $\mathrm{CP}=2,282 \mathrm{~W}^{0.75}+0.356 \mathrm{G}+0.262 \mathrm{EM}$, where $\mathrm{CP}$ is crude protein requirement (g/bird/day), W is body weight ( $\mathrm{kg}$ ), $\mathrm{G}$ is weight gain ( $\mathrm{g} /$ day) and EM is egg mass (g/day).
\end{abstract}

Key Words: broiler breeders hens, factorial method, nitrogen balance, prediction equation, protein requirement

\section{Introdução}

Uma vez que a alimentação das aves reprodutoras de corte é controlada, levam-se em conta para formulação da ração o seu consumo e as exigências por ave por dia, dando ênfase, principalmente, ao consumo de energia. Considerando que os níveis de proteína bruta nas rações de aves reprodutoras pesadas são fixos, isto pode levar a um excessivo consumo deste nutriente durante todo o período produtivo, especialmente no período do pico de produção, em que, normalmente, se aumenta a quantidade de ração, com intuito de elevar o consumo de energia metabolizável pelas aves.

Diversos fatores influenciam as exigências de proteínas: os intrínsecos, como o genótipo, a idade e o peso da ave, e os extrínsecos, nutrição, nível de produção, condições de manejo e alojamento, alimentação durante a cria e recria e a margem de segurança na atribuição das necessidades (Santomá, 1991).

\footnotetext{
${ }_{1}^{1}$ Parte da Tese de Doutorado do primeiro autor, apresentada à FCAV-UNESP-Jaboticabal, São Paulo. Pesquisa financiada pela FAPESP 2 Prof. Dr. do Dep. de Zootecnia, UFRPE, R. Dom Manoel de Medeiros, s/n, Dois Irmãos, Recife, PE. CEP:52.171-900. E.mail: cbviagem@bol.com.br ${ }^{3}$ Prof. Dr. do Dep. de Zootecnia, UNESP, Jaboticabal, SP. E.mail: sakomura@fcav.unesp.br

${ }^{4}$ Estudante de Pós-graduação da UNESP, Jaboticabal, SP.

5 Gerente da GUARAVES Alimentos, Guarabira, PB.
} 
Tendo em vista que o método convencional, com base na avaliação de diferentes níveis de determinado nutriente, conforme o desempenho produtivo das aves, não controla os fatores mencionados, alguns pesquisadores têm recomendado o método fatorial para determinação das exigências nutricionais (Hurwitz \& Bornstein, 1973; Fisher, 1981). Este método se baseia na divisão das exigências dos nutrientes entre mantença, produção e/ou crescimento (Hurwitz \& Bornestein, 1973; Santomá, 1991; Sakomura, 1996), possibilitando a elaboração de equações de predição para facilitar a elaboração de programas nutricionais mais adequados para as aves.

Existem diversas recomendações a partir de estudos para elaboração de equações de predição das exigências protéicas para aves em crescimento (Hurwitz et al., 1978; Scott et al., 1982; Albino et al., 1994; Basaglia, 1996; Silva, 1999; Longo et al., 2000) e poedeiras leves em produção (Hurwitz \& Bornstein, 1973; Scott et al., 1982; Basaglia, 1999), sendo que não há estudos para aves reprodutoras pesadas.

Este trabalho teve como objetivo determinar as exigências de proteína bruta para aves reprodutoras pesadas pelo método fatorial com a finalidade de elaborar uma equação de predição das exigências protéicas para aves na fase de produção.

\section{Material e Métodos}

Os experimentos foram realizados no Setor de Avicultura do Departamento de Zootecnia da Faculdade de Ciências Agrárias e Veterinárias, Câmpus de Jaboticabal.

Determinação das exigências de proteina para mantença

A exigência de proteína bruta para mantença (PBm) foi determinada pela técnica do balanço de nitrogênio. Um ensaio de metabolismo foi realizado com duração de oito dias, sendo quatro dias de adaptação às dietas experimentais e quatro dias para coleta de excretas. Foram utilizadas 48 aves reprodutoras pesadas da linhagem Hubbard HI-Y, com 36 semanas de idade alojadas em galpão aberto em gaiolas de metabolismo $(100 \times 45 \times 40 \mathrm{~cm})$ à temperatura ambiente (média de $23,6^{\circ} \mathrm{C}$ ). As gaiolas eram equipadas com comedouro e bebedouro tipo calha.

Foi utilizado um delineamento inteiramente casualizado, com quatro tratamentos e seis repetições, sendo cada repetição composta por duas aves, distribuídas aleatoriamente aos tratamentos experimentais. Os tratamentos consistiram no fornecimento de quatro dietas isocalóricas com níveis decrescentes de nitrogênio, a fim de proporcionar balanço de nitrogênio positivo, próximo a zero e balanço de nitrogênio negativo. As rações foram formuladas com diferentes níveis de proteína mantendo a mesma relação proteína/aminoácidos (Tabela 1) seguindo as recomendações nutricionais do manual da linhagem recomendada pela Granja Rezende.

A partir da quantidade de ração ingerida e da produção de excretas, durante o período experimental, e os teores de nitrogênio das rações e excretas, foram calculados os valores diários de ingestão, excreção e balanço de nitrogênio. Em seguida, utilizou-se o procedimento proposto por Burnham e Gous (1992) para determinar a exigência de nitrogênio para mantença, por intermédio de uma equação de regressão do balanço de nitrogênio em função da ingestão de nitrogênio. Esta equação fornece, no intercepto do eixo $\mathrm{Y}$, as perdas endógenas de nitrogênio, e, no intercepto do eixo $X$, a exigência de nitrogênio necessária para mantença, a qual multiplicada pelo fator de conversão 6,25 , determinaram-se as estimativas na exigência de $\mathrm{PBm}$. A inclinação da reta (coeficiente de regressão) obtida na equação de regressão do balanço de nitrogênio em função do nitrogênio ingerido forneceu a eficiência de utilização da proteína bruta da dieta.

As amostras de excretas e rações coletadas durante o experimento foram inicialmente armazenadas em freezer, homogeneizadas e em seguida coletada uma amostra para análises laboratoriais de matéria seca e nitrogênio segundo metodologia da AOAC (1990).

Determinação das exigências de proteína para ganho de peso

Para determinação das exigências de proteína para ganho de peso $(\mathrm{PBg})$ foram conduzidos dois ensaios. O primeiro ensaio foi realizado com o objetivo de determinar a exigência líquida de nitrogênio por grama de ganho de peso e o outro para determinar a eficiência de utilização do nitrogênio para ganho de peso $(\mathrm{kg})$.

A partir desses resultados, determinou-se a exigência de nitrogênio para o ganho de peso, dividindo-se a exigência de nitrogênio líquido para o ganho pela eficiência de utilização de nitrogênio, e, ao multiplicar por 6,25, estimaram-se as exigências de PBg.

Para determinar a exigência líquida de nitrogênio 
Tabela 1 - Composição percentual das rações experimentais

Table 1 - Percentage composition of the experimental diets

\begin{tabular}{|c|c|c|c|c|}
\hline \multirow[t]{2}{*}{$\begin{array}{l}\text { Ingredientes }(\%) \\
\text { Ingredients }\end{array}$} & \multicolumn{4}{|c|}{$\begin{array}{l}\text { Níveis de proteína bruta } \\
\text { Crude protein levels }\end{array}$} \\
\hline & $3 \%$ & $6 \%$ & $8 \%$ & $15,5 \%$ \\
\hline Milho & 24,741 & 17,593 & 34,788 & 63,368 \\
\hline Corn & & & & \\
\hline Farelo de soja & - & 7,791 & 9,400 & 21,596 \\
\hline $\begin{array}{l}\text { Soybean meal } \\
\text { Fécula de mandioca } \\
\text { Manioc starch }\end{array}$ & 12,186 & 12,000 & 8,000 & 1,500 \\
\hline $\begin{array}{l}\text { Farinha de mandioca } \\
\text { Manioc meal }\end{array}$ & 45,129 & 48,000 & 35,000 & 3,000 \\
\hline $\begin{array}{l}\text { Óleo vegetal } \\
\text { Soybean oil }\end{array}$ & 2,300 & 2,125 & 1,000 & 0,188 \\
\hline $\begin{array}{l}\text { Fosfato bicálcico } \\
\text { Dicalcium phosphate }\end{array}$ & 2,202 & 2,158 & 2,075 & 1,856 \\
\hline $\begin{array}{l}\text { Calcário } \\
\text { Limestone }\end{array}$ & 7,405 & 7,354 & 7,425 & 7,534 \\
\hline $\begin{array}{l}\text { Salcomum } \\
\text { Salt }\end{array}$ & 0,350 & 0,350 & 0,350 & 0,350 \\
\hline $\begin{array}{l}\text { L-Arginina } \\
\text { L-arginine }\end{array}$ & 0,091 & 0,045 & 0,049 & - \\
\hline $\begin{array}{l}\text { DL-Metionina } 99 \\
\text { Dl-methionine } 99\end{array}$ & 0,052 & 0,110 & 0,120 & 0,207 \\
\hline $\begin{array}{l}\text { L-Lisina HCl } \\
\text { HCl L-lysine }\end{array}$ & 0,095 & 0,034 & 0,048 & - \\
\hline $\begin{array}{l}\text { L-Treonina } \\
\text { L-threonine }\end{array}$ & 0,034 & 0,035 & 0,025 & - \\
\hline $\begin{array}{l}\text { L-Triptofano } \\
\text { L-thryptophan }\end{array}$ & 0,015 & 0,005 & 0,008 & - \\
\hline $\begin{array}{l}\text { Suplemento vitamínico } \\
\text { Vitamin mix }\end{array}$ & 0,300 & 0,300 & 0,300 & 0,300 \\
\hline $\begin{array}{l}\text { Suplemento mineral }{ }^{1} \\
\text { Mineral mix }\end{array}$ & 0,100 & 0,100 & 0,100 & 0,100 \\
\hline $\begin{array}{l}\text { Areia lavada } \\
\text { Washed sand } \\
\text { Composição calculada } \\
\text { Calculated composition }\end{array}$ & - & 2,000 & 1,312 & - \\
\hline $\begin{array}{l}\text { Proteína bruta, } \% \\
\text { Crude protein }\end{array}$ & 3,000 & 6,000 & 8,000 & 15,500 \\
\hline $\begin{array}{l}\text { Energia metabolizável, } \mathrm{kcal} / \mathrm{kg} \\
\text { Metabolizable energy }\end{array}$ & 2.825 & 2.825 & 2.825 & 2.825 \\
\hline $\begin{array}{l}\text { Metionina, \% } \\
\text { Methionine }\end{array}$ & 0,094 & 0,191 & 0,241 & 0,457 \\
\hline $\begin{array}{l}\text { Metionina }+ \text { cistina, } \% \\
\text { Methionine }+ \text { cistine }\end{array}$ & 0,138 & 0,276 & 0,368 & 0,720 \\
\hline $\begin{array}{l}\text { Arginina, } \% \\
\text { Arginine }\end{array}$ & 0,183 & 0,366 & 0,488 & 0,947 \\
\hline $\begin{array}{l}\text { Treonina, \% } \\
\text { Threonine }\end{array}$ & 0,117 & 0,234 & 0,312 & 0,604 \\
\hline $\begin{array}{l}\text { Triptofano, \% } \\
\text { Thryptophan }\end{array}$ & 0,039 & 0,078 & 0,104 & 0,200 \\
\hline $\begin{array}{l}\text { Lisina, \% } \\
\text { Lysine }\end{array}$ & 0,150 & 0,300 & 0,400 & 0,772 \\
\hline $\begin{array}{l}\text { Cálcio, } \% \\
\text { Calcium }\end{array}$ & 3,390 & 3,390 & 3,390 & 3,390 \\
\hline $\begin{array}{l}\text { Fósforo disponível, \% } \\
\text { Available phosphorus }\end{array}$ & 0,440 & 0,440 & 0,440 & 0,440 \\
\hline
\end{tabular}

${ }^{1}$ Os suplementos vitamínico e mineral foram formulados para atender as exigências nutricionais das aves e produzidos pela Granja Rezende (Vitamin and mineral mix was formulated to meet the nutritional requirements of broiler breeders and were produced at the Granja Rezende). 
para o ganho de peso foram utilizadas 60 aves reprodutoras pesadas da linhagem Hubbard HI-Y com 26 semanas de idade, alojadas em galpão aberto numa bateria com gaiolas medindo $60 \times 50 \times 40 \mathrm{~cm}$, sendo colocadas 2 aves/gaiola à temperatura ambiente (média de $22,9^{\circ} \mathrm{C}$ ). As aves foram distribuídas em três grupos de 20 aves com o objetivo de se acompanhar semanalmente o peso corporal, ganho de peso e teores de nitrogênio corporal por meio de abates semanais durante o período de 26 a 33 semanas de idade. Antes do abate, as aves foram inicialmente submetidas a jejum de 24 horas e mortas por deslocamento cervical, em seguida foram pesadas e mergulhadas em água quente para posterior retirada das penas e pesadas novamente. As amostras de penas foram cortadas e as carcaças serradas, moídas e secas em estufa a $55^{\circ} \mathrm{C}$ por 72 horas. Posteriormente, foram realizadas as análises de matéria seca e nitrogênio da carcaça e penas, segundo metodologia descrita pela AOAC (1990).

O fornecimento de ração foi controlado de acordo com a recomendação da linhagem e com a produção das aves, e a água fornecida à vontade. A fórmula da ração fornecida encontra-se na Tabela 2 .

A partir das análises de nitrogênio na carcaça e

Tabela 2 - Composição percentual das rações experimentais

Table 2 - Percentage composition of the experimental diets

\begin{tabular}{|c|c|c|}
\hline $\begin{array}{l}\text { Ingredientes (\%) } \\
\text { Ingredients }\end{array}$ & $\begin{array}{l}\text { Ração de produção } \\
\text { Production ration }\end{array}$ & $\begin{array}{l}\text { Ração com baixo cálcio } \\
\text { Low calcium ration }\end{array}$ \\
\hline Milho & 68,670 & 57,850 \\
\hline Corn & & \\
\hline Farelo de soja & 20,991 & 17,500 \\
\hline Soybean meal & & \\
\hline $\begin{array}{l}\text { Farelo de trigo } \\
\text { Wheat meal }\end{array}$ & - & 16,000 \\
\hline $\begin{array}{l}\text { Fosfato bicálcico } \\
\text { Dicalcium phosphate }\end{array}$ & 1,840 & 1,647 \\
\hline $\begin{array}{l}\text { Calcário } \\
\text { Limestone }\end{array}$ & 7,558 & - \\
\hline $\begin{array}{l}\text { Sal comum } \\
\text { Salt }\end{array}$ & 0,350 & 0,335 \\
\hline $\begin{array}{l}\text { DL-Metionina } 99 \\
\text { DL-methionine } 99\end{array}$ & 0,191 & 0,197 \\
\hline $\begin{array}{l}\text { L-Lisina } \\
\text { HCl L-lysine }\end{array}$ & - & 0,044 \\
\hline $\begin{array}{l}\text { Suplemento vitamínico } \\
\text { Vitamin mix }\end{array}$ & 0,300 & 0,300 \\
\hline $\begin{array}{l}\text { Suplemento mineral } \\
\text { Mineral mix }\end{array}$ & 0,100 & 0,100 \\
\hline $\begin{array}{l}\text { Areia lavada } \\
\text { Washed sand } \\
\text { Composição calculada } \\
\text { Calculated composition }\end{array}$ & - & 6,028 \\
\hline $\begin{array}{l}\text { Proteína bruta, } \% \\
\text { Crude protein }\end{array}$ & 15,500 & 15,500 \\
\hline $\begin{array}{l}\text { Energia metabolizável, } \mathrm{kcal} / \mathrm{kg} \\
\text { Metabolizable energy }\end{array}$ & 2.825 & 2.620 \\
\hline $\begin{array}{l}\text { Metionina, } \% \\
\text { Methionine }\end{array}$ & 0,446 & 0,446 \\
\hline $\begin{array}{l}\text { Metionina }+ \text { Cistina, } \% \\
\text { Methionine }+ \text { cistine }\end{array}$ & 0,715 & 0,715 \\
\hline $\begin{array}{l}\text { Lisina, } \% \\
\text { Lysine }\end{array}$ & 0,760 & 0,760 \\
\hline $\begin{array}{l}\text { Cálcio, } \% \\
\text { Calcium }\end{array}$ & 3,390 & 0,466 \\
\hline $\begin{array}{l}\text { Fósforo disponível, \% } \\
\text { Available phosphorus }\end{array}$ & 0,410 & 0,410 \\
\hline
\end{tabular}

\footnotetext{
${ }^{1}$ Os suplementos vitamínico e mineral foram formulados para atender as exigências nutricionais das aves e produzidos pela Granja Rezende (Vitamin and mineral mix was formulated to meet the nutritional requirements of broiler breeders and were produced at the Granja Rezende).
} 
penas quantificou-se nitrogênio depositado (g). Assim, estimaram-se as exigências líquidas de nitrogênio para o ganho de peso, a partir da regressão linear entre o teor de nitrogênio corporal $(\mathrm{g})$, em função do peso corporal $(\mathrm{g})$.

Para determinar a eficiência de utilização do nitrogênio para o ganho de peso foi conduzido outro ensaio com aves reprodutoras pesadas Hubbard HIY, durante o período de 26 a 33 semanas de idade, entretanto as aves foram mantidas fora de produção com o objetivo de se determinar apenas a eficiência de utilização do nitrogênio para o ganho de peso, isoladamente. Para isto, as aves foram alojadas individualmente em gaiolas $(50 \times 45 \times 40 \mathrm{~cm})$, com bebedouro e comedouro tipo calha, para o controle individual das aves. A temperatura ambiente no galpão durante o período experimental foi de $22,9^{\circ} \mathrm{C}$. As aves que entravam em produção eram eliminadas do experimento. Foram alojadas 60 aves distribuídas em 3 grupos de 20 aves, conforme o experimento anterior.

A ração experimental foi formulada com baixo nível de cálcio (Tabela 2), para evitar que as aves entrassem em postura. Além disso, as aves foram mantidas apenas com luz natural, não se adotando nenhum programa de luz.

O fornecimento de ração foi controlado de acordo com o peso das aves e a água fornecida à vontade.

Foi realizado o controle de peso corporal semanalmente e abatidas duas aves (peso médio) por semana de cada grupo para determinar a deposição de nitrogênio corporal. Os abates e as análises da composição da carcaça foram realizados como descrito no experimento anterior.

A eficiência de utilização do nitrogênio para ganho de peso foi determinada por meio da seguinte fórmula: $k g=\mathrm{NRg} /(\mathrm{NI}-\mathrm{Nm})$, em que $\mathrm{kg}=$ eficiência da utilização do nitrogênio para ganho de peso, $\mathrm{NRg}=$ nitrogênio retido no ganho de peso $\left(\mathrm{kcal} / \mathrm{kg}^{0,75} / \mathrm{dia}\right), \mathrm{NI}=$ nitrogênio ingerido ( $\left.\mathrm{kcal} / \mathrm{kg}^{0,75} / \mathrm{dia}\right), \mathrm{Nm}=$ nitrogênio para mantença $\left(\mathrm{kcal} / \mathrm{kg}^{0,75} / \mathrm{dia}\right)$. O valor das exigências de nitrogênio para mantença $(\mathrm{Nm})$ utilizado nos cálculos foi determinado no ensaio de metabolismo anteriormente descrito.

Determinação das exigências de proteina para produção de ovos

Foi conduzido um ensaio com 48 aves reprodutoras pesadas da linhagem Hubbard HI-Y, alojadas em gaiolas $(100 \times 45 \times 40 \mathrm{~cm})$, sendo 4 aves/gaiola no período de 31 a 37 semanas de idade. As gaiolas eram equipadas com bebedouro nipple e comedouro tipo calha. A temperatura média durante o período experimental foi de $23^{\circ} \mathrm{C}$.

Durante o período experimental, foram quantificados semanalmente o peso das aves, a produção e o peso dos ovos. Uma amostra de 6 ovos de cada grupo uma vez por semana foi coletada, homogeneizada por 2 minutos em liqüidificador e armazenada em freezer. Em seguida foram secas em estufa $\left(55^{\circ} \mathrm{C}\right.$ por 72 horas $)$, moídas e submetidas às análises laboratoriais de matéria seca, energia bruta, nitrogênio, extrato etéreo e cinzas, segundo metodologia descrita pela AOAC (1990).

A ração experimental para aves em produção foi formulada para atender as exigências nutricionais das aves, segundo as recomendações da linhagem (Tabela 2). O fornecimento de ração foi realizado de acordo com o peso das aves e a produção de ovos seguindo as recomendações do manual da linhagem e a água fornecida à vontade.

A eficiência de utilização do nitrogênio para produção de ovos $(k o)$ foi determinada considerando o nitrogênio retido no ovo (NRo) dividido pelo nitrogênio ingerido (NI), descontando-se o nitrogênio destinado para mantença $(\mathrm{Nm})$ e para ganho de peso $(\mathrm{Ng})$. Portanto, $k o=$ NRo $/[\mathrm{NI}-(\mathrm{Nm}+\mathrm{Ng})]$.

As exigências de nitrogênio para produção de ovos (No) foram determinadas considerando-se a composição média de nitrogênio dos ovos dividido pela eficiência de utilização do nitrogênio $(k o)$, que, ao ser multiplicado por 6,25 , determinaram-se as exigências de proteína bruta para produção de ovos (PBo).

Elaboração da equação de predição das exigências de proteina para reprodutoras pesadas na fase de produção

Considerando-se as exigências de nitrogênio para mantença, ganho de peso e produção de ovos, foi elaborada uma equação de predição das exigências de proteína para reprodutoras pesadas na fase de produção.

\section{Análises estatísticas}

Para determinar as exigências de nitrogênio para mantença e para o ganho de peso foram realizadas análises de regressão por intermédio do programa PROC REG do SAS for Windows v.6.12 (1996). 


\section{Resultados e Discussão}

\section{Exigência de proteina para mantença}

$\mathrm{Na}$ Tabela 3 estão apresentados os dados da ingestão, excreção e balanço de nitrogênio obtidos durante o período experimental. Observa-se que a ingestão de nitrogênio, bem como o nitrogênio excretado e o balanço de nitrogênio foram proporcionais aos teores de nitrogênio das rações, tendo em vista que o consumo das rações foi controlado, proporcionando a mesma ingestão de todos os nutrientes, exceto o nitrogênio e os aminoácidos para os diferentes tratamentos.

A relação do balanço de nitrogênio em função da ingestão de nitrogênio resultou na seguinte equação de regressão, $\mathrm{BN}=-0,2216+0,6079 \mathrm{NI}\left(\mathrm{g} / \mathrm{kg}^{0,75} / \mathrm{dia}\right)$, $\mathrm{R}^{2}=0,76$. As perdas endógenas da ave em jejum, isto é, o nitrogênio excretado quando a ingestão de nitrogênio é nula foi $221,6 \mathrm{mg}$ de N/ $\mathrm{kg}^{0,75} / \mathrm{dia}$. A eficiência de utilização do nitrogênio medida pela inclinação da reta foi de 0,6079 , como pode ser observado na Figura 1. Atribuindo-se o valor zero para o $\mathrm{BN}$, determinou-se a quantidade de nitrogênio utilizado para mantença $(\mathrm{Nm})$ de $365 \mathrm{mg}$ de $\mathrm{N} / \mathrm{kg}^{0,75} /$ dia ou $2.282 \mathrm{mg} \mathrm{PB} / \mathrm{kg}^{0,75} / \mathrm{dia}$.

Os dados das exigências de nitrogênio para mantença para aves são bastante escassos na literatura. Scott et al. (1982) recomendam para poedeiras leves em produção valores de $201 \mathrm{mgN} / \mathrm{kg}^{0,75} /$ dia para o período de 21 a 42 semanas e $224 \mathrm{mgN} / \mathrm{kg}^{0,75}$ / dia para o período de 42 semanas até o descarte. Por outro lado, Basaglia (1999) encontrou a exigência de $307 \mathrm{mgN} / \mathrm{kg}^{0,75} /$ dia para poedeiras leves usando a técnica do balanço de nitrogênio, valor mais próximo

Tabela 3 - Médias da ingestão de nitrogênio (NI), excreção de nitrogênio (NE) e balanço de nitrogênio (BN) das aves durante o período experimental e seus respectivos desvios-padrão

Table 3 - Mean nitrogen intake (NI), nitrogen excretion (NE) and nitrogen balance (NB) of the birds during the experimental period and its respective standard deviations

\begin{tabular}{|c|c|c|c|}
\hline $\begin{array}{l}\text { Níveis de proteína } \\
\text { das dietas } \\
\text { Protein levels (\%) }\end{array}$ & $\begin{array}{l}\mathrm{NI} \\
N I\end{array}$ & $\begin{array}{l}\mathrm{NE} \\
N E\end{array}$ & $\begin{array}{l}\mathrm{BN} \\
N B\end{array}$ \\
\hline & \multicolumn{3}{|c|}{$\begin{array}{c}\mathrm{g} / \mathrm{kg}^{0,75} / \mathrm{dia} \\
\text { g/bird/day }\end{array}$} \\
\hline 15,50 & $2,38+0,04$ & $1,21+0,44$ & $1,17+0,45$ \\
\hline 8,00 & $1,43+0,03$ & $0,68+0,18$ & $0,75+0,16$ \\
\hline 6,00 & $0,83+0,06$ & $0,49+0,15$ & $0,34+0,12$ \\
\hline 3,00 & $0,49+0,03$ & $0,51+0,11$ & $-0,02+0,13$ \\
\hline
\end{tabular}

ao encontrado neste trabalho com reprodutoras pesadas, de $365 \mathrm{mgN} / \mathrm{kg}^{0,75} /$ dia, usando a mesma técnica.

Albino et al. (1994), trabalhando com duas linhagens de poedeiras leves em crescimento, utilizando a técnica do abate comparativo, obtiveram exigência de nitrogênio para mantença de 362,5 e 475,0 mg $\mathrm{N} / \mathrm{kg}^{0,75} /$ dia para as linhagens Embrapa e Lohman, respectivamente.

Resultados superiores foram obtidos por Macleod (1990), quando determinou as exigências de nitrogênio para mantença de frangos de corte fêmea, pela técnica do balanço de nitrogênio, obtendo 900 e $1110 \mathrm{mg} / \mathrm{kg}^{0,75} / \mathrm{dia}$, quando utilizou dietas com baixa e alta proteína, respectivamente. Este resultado evidencia que excessivas quantidades de proteína na dieta levam o animal a se adaptar, utilizando a proteína como fonte de energia, levando a maiores exigências de aminoácidos para mantença, devido ao aumento na taxa de gluconeogênese da proteína consumida em excesso. Segundo Boorman (1981), as exigências de proteína para mantença em animais adultos são diferentes daquelas para animais em crescimento.

Conforme a equação de regressão do nitrogênio ingerido em funçãodo balanço denitrogênio, determinou-se a eficiência de utilização de 0,6079 (inclinação da reta), próxima à encontrada por Basaglia (1999) de 0,5895 , determinada com poedeiras leves, que foi um pouco superior ao valor observado por Silva (1999) para matrizes pesadas em crescimento de 0,5537 . Por outro lado, valores superiores foram encontrados por Basaglia (1996), de 0,6721, para aves de postura em crescimento, e por Scott (1982), de 0,67, para frangos de corte.

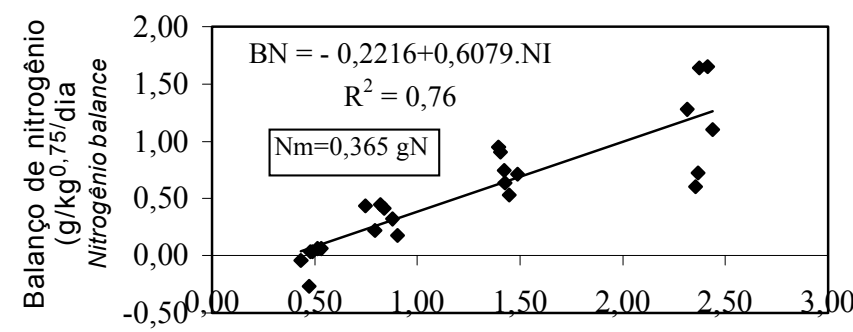

Nitrogênio ingerido $\left(\mathrm{g} / \mathrm{kg}^{0,75} / \mathrm{dia}\right)$ Nltrogen intake $\left(\mathrm{g} / \mathrm{kg}^{.75} /\right.$ day)

Figura 1 - Equação de regressão do balanço de nitrogênio, em função da ingestão de nitrogênio.

Figure 1 - Regression equation of nitrogen balance, in function of nitrogen intake.

R. Bras. Zootec., v.31, n.3, p.1204-1213, 2002 
Exigência de proteina para ganho de peso

Na Tabela 4 estão apresentados os dados médios de peso e composição corporal das aves, obtidos no período de 26 a 33 semanas de idade. Pode-se observar que a composição em proteína corporal é estável até 29 semanas de idade e, à partir dessa idade, tende a diminuir em termos percentuais, pois as aves, com o passar da idade, diminuem a taxa de crescimento protéico e aumentam o teor de gordura corporal, até mesmo porque a maior parte da proteína consumida é destinada à produção de ovos.

De acordo com a equação que relaciona o nitrogênio corporal com o peso corporal, o coeficiente da regressão $(0,0228)$ indica a deposição de $0,0228 \mathrm{~g}$ de nitrogênio para cada grama de ganho de peso. Por- tanto a exigência líquida de nitrogênio para ganho de peso foi de 22,80 mg N/g (Figura 2).

$\mathrm{Na}$ Tabela 5 estão apresentados os resultados obtidos no segundo ensaio, onde as aves receberam ração com baixo nível de cálcio e ausência de luz artificial, para evitar a produção de ovos. Pela diferença entre o nitrogênio ingerido e o nitrogênio destinado à mantença $(0,90 \mathrm{~g} / \mathrm{ave} / \mathrm{dia})$, calculou-se o nitrogênio utilizado para o ganho (média de 2,29 g/ave/dia). A eficiência de utilização do nitrogênio para o ganho $\left(k_{g}\right)$ foi determinada pela relação do nitrogênio retido no ganho e nitrogênio ingerido para o ganho (NRg/NIg).

A eficiência de utilização do nitrogênio para o ganho de peso $(\mathrm{kg})$ obtida foi de $40 \%$, inferior ao preconizado por Scott et al. (1982) que consideram a

Tabela 4 - Médias dos valores de peso (g) e composição corporal (\%) para o período de 26 a 33 semanas de idade e seus respectivos desvios-padrão

Table 4 - Weight $(g)$ and body composition mean value (\%) for birds between 26 and 33 weeks old and its respective standard deviations

\begin{tabular}{|c|c|c|c|c|c|c|c|}
\hline $\begin{array}{l}\text { Idade (Semanas) } \\
\text { Age (weeks) }\end{array}$ & $\begin{array}{l}\text { Peso }(\mathrm{g}) \\
\text { Weight }\end{array}$ & $\begin{array}{l}\text { Penas } \\
\text { Feathers }\end{array}$ & $\begin{array}{l}\text { Água } \\
\text { Water }\end{array}$ & $\begin{array}{c}\text { Cinza } \\
\text { Ash } \\
\%\end{array}$ & $\begin{array}{l}\text { Gordura } \\
\text { Fat }\end{array}$ & $\begin{array}{l}\text { Proteína } \\
\text { Protein }\end{array}$ & $\begin{array}{c}\text { Energia } \\
\text { Energy } \\
(\mathrm{kcal} / \mathrm{kg})\end{array}$ \\
\hline 26 & $3043+6,24$ & $5,03+0,01$ & $63,91+0,78$ & $3,18+0,21$ & $13,78+0,73$ & $16,32+0,05$ & $2,22+0,26$ \\
\hline 27 & $3400+11,79$ & $4,68+0,06$ & $63,41+1,28$ & $2,96+0,16$ & $14,27+0,95$ & $16,07+0,23$ & $2,23+0,13$ \\
\hline 28 & $3599+21,36$ & $4,02+0,01$ & $63,86+3,30$ & $2,92+0,08$ & $13,88+3,12$ & $16,08+0,77$ & $2,31+0,27$ \\
\hline 29 & $3695+40,04$ & $3,98+0,02$ & $61,23+1,28$ & $3,24+0,12$ & $15,52+1,25$ & $16,50+0,18$ & $2,43+0,20$ \\
\hline 30 & $3743+38,84$ & $4,63+0,08$ & $61,40+0,20$ & $3,06+0,35$ & $16,88+1,17$ & $15,76+0,45$ & $2,56+0,21$ \\
\hline 31 & $3731+30,01$ & $4,53+0,04$ & $64,25+0,80$ & $3,07+0,27$ & $13,71+0,55$ & $15,41+0,28$ & $2,31+0,28$ \\
\hline 32 & $3886+26,15$ & $4,81+0,10$ & $61,32+1,83$ & $3,08+0,11$ & $15,88+2,20$ & $16,63+0,19$ & $2,53+0,35$ \\
\hline 33 & $3961+14,36$ & $3,72+0,01$ & $62,27+0,65$ & $2,97+0,19$ & $16,02+0,34$ & $15,77+0,20$ & $2,47+0,07$ \\
\hline
\end{tabular}

${ }^{1}$ Composição média das penas: Água $=7,00+0,28 \%$, Extrato etéreo $=1,41+0,33 \%$, Cinzas $=0,76+0,11 \%$, proteína bruta $=88,36+0,77 \%$ e energia bruta $=5,35+0,07 \mathrm{kcal} / \mathrm{g}$ (Composition of feathers: water $=7.00 \%$, fat $=1.41 \%$, ash $=0.76 \%$, crude protein $=88.36 \%$ and crude energy $=$ $5.35 \%)$.

eficiência de utilização do nitrogênio da dieta para ser depositado no corpo de aves em produção o valor de $55 \%$. Albino et al. (1994) determinaram para frangas de postura em crescimento uma eficiência de $61,88 \%$ e Macleod (1991) encontrou 46\% em experimento com frangos de corte.

Diferenças nas eficiências de utilização do nitrogênio podem estar relacionadas a composição da dieta (Boorman, 1981; Scott et al., 1982; Nieto et al., 1995), pois a digestibilidade da dieta e o fornecimento adequado de aminoácidos podem provocar deficiência ou desequilíbrio nutricional, levando, assim, à subutilização dos mesmos e, em alguns casos, à diminuição da deposição protéica e ao aumento na deposição de gordura corporal.

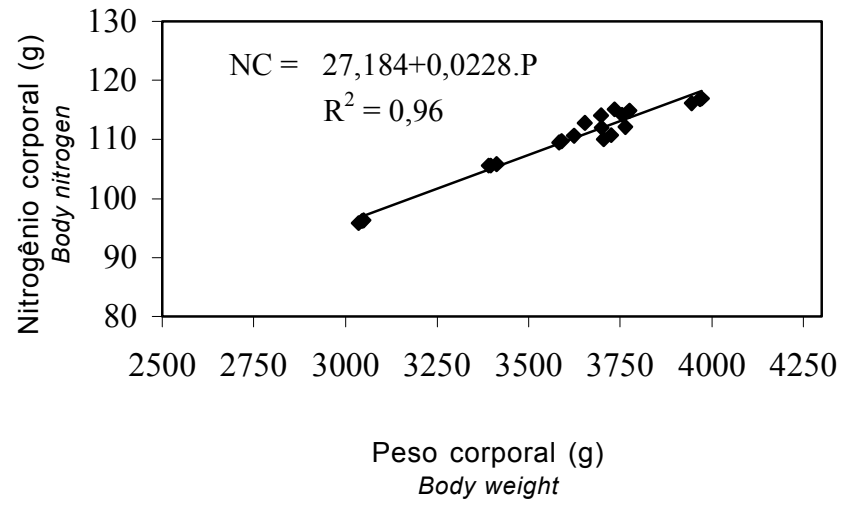

Figura 2 - Equação de regressão da relação do nitrogênio e o peso corporal para determinação das exigências de nitrogênio líquido.

Figure 2 - Nitrogen and body weight regression equation to determine net nitrogen requirement. 
Tabela 5 - Médias de peso inicial $(\mathrm{PI})$ e final $(\mathrm{PF})$, ingestão nitrogênio (NI), nitrogênio para mantença (Nm), nitrogênio ingerido para o ganho $(\mathrm{Nlg})$, nitrogênio retida no ganho $(\mathrm{NRg})$ e a eficiência de utilização do nitrogênio (\%)

Table 5 - Mean initial (IW) and final weight (FW), nitrogen intake (NI), nitrogen for maintenance (Nm), nitrogen intake for gain (NIg), nitrogen retention for gain $(\mathrm{RNg})$ and nitrogen use efficiency (\%)

\begin{tabular}{|c|c|c|c|c|c|c|c|}
\hline $\begin{array}{l}\text { Grupos } \\
\text { Groups }\end{array}$ & $\begin{array}{c}\mathrm{PI}(\mathrm{g}) \\
I W \\
\end{array}$ & $\begin{array}{c}\mathrm{PF}(\mathrm{g}) \\
F W\end{array}$ & $\begin{array}{l}\mathrm{NI} \\
N I\end{array}$ & $\begin{array}{c}\mathrm{Nm}^{1} \\
\mathrm{Nm}\end{array}$ & $\begin{array}{c}\mathrm{NIg}^{2} \\
\mathrm{NIg}\end{array}$ & $\begin{array}{l}\mathrm{NRg} \\
R N g\end{array}$ & $\begin{array}{l}\mathrm{kg}^{3} \\
(\%)\end{array}$ \\
\hline & & & & & $\begin{array}{l}\text { g/ave/dia } \\
\text { g/bird/day }\end{array}$ & & \\
\hline $\mathrm{A}$ & 2.844 & 3.855 & 3,20 & 0,89 & 2,30 & 0,94 & 41 \\
\hline B & 2.825 & 3.791 & 3,14 & 0,88 & 2,26 & 0,96 & 42 \\
\hline $\mathrm{C}$ & 2.856 & 3.849 & 3,20 & 0,92 & 2,28 & 0,85 & 37 \\
\hline Médias & $2851+71$ & $3833+125$ & $3,19+0,02$ & $0,90+0,02$ & $2,29+0,02$ & $0,91+0,05$ & $40+1,97$ \\
\hline
\end{tabular}

${ }^{1} \mathrm{Nm}=2,282 \cdot \mathrm{P}^{0,75}$ ou PBm $=0,365, \mathrm{p}^{0,75}\left(\mathrm{Nm}=2.282 \mathrm{~W}^{0.75)}\right.$ or $\left.\mathrm{CP}=0.365 \cdot \mathrm{W}^{0.75}\right)$.

${ }^{2} \mathrm{NIg}=\mathrm{NI}-\mathrm{Nm}(\mathrm{N} / \mathrm{g}=\mathrm{NI}-\mathrm{Nm})$.

${ }^{3} \mathrm{~kg}=\mathrm{NRg} / \mathrm{NIg}(\mathrm{kg}=\mathrm{RNg} / \mathrm{N} / \mathrm{g})$

Considerando-se a exigência de nitrogênio líquido para o ganho de peso $(0,0228 \mathrm{~g} \mathrm{~N} / \mathrm{g}$ de ganho) e a eficiência de utilização do nitrogênio de $40 \%$, determinou-se a exigência de $57 \mathrm{mg}$ de $\mathrm{N} / \mathrm{g}$ de ganho ou $356 \mathrm{mg}$ de $\mathrm{PB} / \mathrm{g}$ de ganho. Resultados superiores foram encontrados para poedeiras leves em produção, de $481 \mathrm{mg} \mathrm{PB/g}$ de ganho (Basaglia, 1999). As exigências de nitrogênio são dependentes das taxas de crescimento e do potencial de crescimento do animal, e são influenciadas pelo consumo de proteína, qualidade da proteína e fornecimento de energia (Boorman, 1981).

\section{Exigência de proteína para produção de ovos}

$\mathrm{Na}$ Tabela 6 estão apresentados os dados obtidos de composição química dos ovos durante o período experimental de 31 a 37 semanas de idade. Os valores médios determinados de umidade $(70,74 \%)$, proteína bruta $(12,25 \%)$, extrato etéreo $(7,60 \%)$ dos ovos foram semelhantes aos determinados por Sakomura (1989) de 68,2; 12,05 e 7,71\%, respectivamente. Quanto ao teor de cinzas obtido no presente estudo $(8,02 \%)$, foram superiores ao obtido por Sakomura (1989) de 6,23\%. Segundo Fisher (1970), citado por Santomá (1991), o conteúdo em proteína do ovo diminui $2,8 \mathrm{mg} / \mathrm{g}$ ao longo do ano de postura, sendo difícil considerar esta variação; o autor recomenda o valor de $11,25 \%$ de proteína do ovo, valor um pouco inferior ao obtido no presente trabalho $(12,25 \%)$, o qual é similar ao citado por Scott et al. (1982), aproximadamente $12 \%$.

Os resultados de composição química dos ovos variaram pouco com a idade no período estudado (Tabela 6). Por outro lado, Chwalibog (1992), trabalhando com poedeiras leves, no período de 27 a 48 semanas de idade, observou que, com o aumento na idade, aumentou o teor de energia e proteína apenas

Tabela 6 - Composição média dos ovos (\%) produzidos no período de 31 a 37 semanas de idade, e seus respectivos desvios-padrão

Table 6 - Egg composition (\%) produced from 31 to 37 weeks old and its respective standard deviations

\begin{tabular}{|c|c|c|c|c|c|}
\hline \multirow{2}{*}{$\begin{array}{l}\text { Idade (Semanas) } \\
\text { Age (weeks) }\end{array}$} & Água & Cinzas & Gordura & Proteína & \multirow{2}{*}{$\begin{array}{c}\text { Energia } \\
\text { Energy } \\
\mathrm{kcal} / \mathrm{g}\end{array}$} \\
\hline & Water & Ash & Fat & Protein & \\
\hline $31-32$ & 70,58 & 8,08 & 7,77 & 11,67 & 1,64 \\
\hline $32-33$ & 70,77 & 7,89 & 7,56 & 12,50 & 1,48 \\
\hline $33-34$ & 71,85 & 7,15 & 7,46 & 12,22 & 1,47 \\
\hline $34-35$ & 70,59 & 8,13 & 7,50 & 12,36 & 1,55 \\
\hline $35-36$ & 70,85 & 8,42 & 7,43 & 12,46 & 1,52 \\
\hline $36-37$ & 69,82 & 8,42 & 7,87 & 12,27 & 1,56 \\
\hline Médias & $70,74+0,89$ & $8,02+0,74$ & $7,60+0,34$ & $12,25+0,55$ & $1,54+0,10$ \\
\hline
\end{tabular}

\section{R. Bras. Zootec., v.31, n.3, p.1204-1213, 2002}


na primeira semana. Por outro lado, esse autor comenta que poucos trabalhos descrevem este efeito.

A partir dos valores determinados das exigências de nitrogênio para mantença e ganho de peso, determinou-se o quanto de nitrogênio foi ingerido pelas aves, para produção de ovos. Assim, dividindo-se o valor de nitrogênio depositado nos ovos, pelo valor de nitrogênio ingerido para tal destino, determinouse a eficiência de utilização do nitrogênio para produção, o qual foi $46,80 \%$, conforme apresentado na Tabela 7.

A eficiência de utilização do nitrogênio para produção encontrada neste trabalho foi inferior àquela de $55 \%$ relatada por Scott et al. (1982) e, por outro lado, superior à de $38 \%$ determinada por Basaglia (1999) com poedeiras leves. Apesar das eficiências de utilização de nitrogênio para ganho de peso $(40 \pm 2 \%)$ e para produção de ovos $(46,80 \pm 4,5 \%)$ terem sido próximos, foi importante determinar as eficiências isoladamente para cada função, visando a determinar as exigências de proteína bruta para o ganho de peso e produção de ovos com maior precisão. A maioria dos trabalhos considera a mesma eficiência para ambas as funções, talvez pela dificuldade em isolar ganho de peso e produção de ovos para aves que estão em produção.

As exigências de proteína para produção de ovos foi determinada a partir do valor médio de proteína

Tabela 7 - Médias dos valores de peso corporal (PC), nitrogênio ingerido (NI), nitrogênio para mantença (Nm), nitrogênio para o ganho $(\mathrm{Ng})$, nitrogênio retido no ovo (NRo) e eficiência de utilização do nitrogênio para produção de ovos $(k o)$

Table 7 - Mean body weight (BW), nitrogen intake (NI), nitrogen for maintenance (Nm), nitrogen for weight gain ( $\mathrm{Ng}$ ), nitrogen retained in the egg (NRe) and nitrogen use efficiency for egg production (ke)

\begin{tabular}{|c|c|c|c|c|c|c|}
\hline \multirow{2}{*}{$\begin{array}{l}\text { Idade } \\
\text { (Semanas) } \\
\text { Age (Weeks) }\end{array}$} & $\begin{array}{l}\mathrm{PC} \\
B W\end{array}$ & $\begin{array}{l}\mathrm{NI} \\
N I\end{array}$ & $\mathrm{Nm}^{1}$ & $\mathrm{NIg}^{2}$ & $\mathrm{NRg}$ & \multirow{2}{*}{$\begin{array}{l}k o^{3} \\
(\%)\end{array}$} \\
\hline & (g) & \multicolumn{4}{|c|}{$\begin{array}{l}\text { gN/ave/dia } \\
\text { gN/bird/day }\end{array}$} & \\
\hline $31-32$ & 3781 & 3,70 & 0,99 & 0,38 & 1,01 & 43,08 \\
\hline $32-33$ & 2859 & 3,83 & 1,00 & 0,65 & 1,14 & 52,47 \\
\hline $33-34$ & 3918 & 3,83 & 1,01 & 0,48 & 1,05 & 44,79 \\
\hline $34-35$ & 3991 & 3,83 & 1,02 & 0,60 & 1,12 & 51,29 \\
\hline $35-36$ & 3993 & 3,83 & 1,03 & 0,30 & 1,14 & 45,76 \\
\hline $36-37$ & 4027 & 3,86 & 1,03 & 0,27 & 1,10 & 43,83 \\
\hline Médias & $3901+16$ & $3,86+0,04$ & $1,01+0,02$ & $0,45+0,26$ & $1,09+0,09$ & $46,80+4,56$ \\
\hline
\end{tabular}

${ }^{1} \mathrm{Nm}=0,365 \cdot \mathrm{P}^{0,75}\left(\mathrm{Nm}=0,365 \cdot W^{0,75}\right)$.

$2 \mathrm{Ng}=0,057 . \mathrm{G}(\mathrm{Ng}=0,057 . \mathrm{G})$.

${ }^{3} \mathrm{ko}=\mathrm{NRo} /[\mathrm{NI}-(\mathrm{Nm}+\mathrm{Ng})](\mathrm{ke}=\mathrm{NRo} /[\mathrm{NI}-(\mathrm{Nm}+\mathrm{Ng})]$.

dos ovos (12,25 g PB/100 g) e da eficiência de utilização da proteína $(46,80 \%)$, obtendo-se, portanto, exigência de $0,262 \mathrm{~g} \mathrm{~PB} / \mathrm{g}$ de ovo.

\section{Conclusões}

A partir dos resultados encontrados, elaborou-se a seguinte equação de predição das exigências protéicas para aves reprodutoras pesadas na fase de produção: $\mathrm{PB}=2,282 . \mathrm{P}^{0,75}+0,356 . \mathrm{G}+0,262 . \mathrm{MO}$, onde $\mathrm{PB}$ é a exigência de proteína bruta (g/ave/dia), $\mathrm{P}$ o peso corporal $(\mathrm{kg})$, G o ganho de peso (g/dia) e MO a massa de ovos (g/dia).

\section{Agradecimento}

À Fundação de Amparo à Pesquisa do Estado de São Paulo (FAPESP), pelo suporte Financeiro.

\section{Literatura Citada}

ALBINO, L.F.T.; FIALHO, F.B.; BELLAVER, C. et al. Estimativas das exigências de energia e proteína para frangas de postura em recria. Pesquisa Agropecuária Brasileira, v.29, n.10, p.1625-1629, 1994.

ASSOCIATION OF OFFICIAL ANALYTICAL CHEMISTS AOAC. AGRICULTURAL CHEMISTS. Official methods of analysis. 16.ed. Washington, D.C.: 1990. 1094p.

BASAGLIA, R. Estimativas das exigências de proteína para 
frangas leves de postura de 1 a 18 semanas de idade. Jaboticabal: Universidade Estadual Paulista, 1996. 79p. Dissertação (Mestrado em Zootecnia) - Universidade Estadual Paulista, 1996.

BASAGLIA, R. Equações de predição das exigências das exigências de energia e proteína para poedeiras leves. Jaboticabal: Universidade Estadual Paulista, 1999. 158p. Tese (Doutorado em Zootecnia) - Universidade Estadual Paulista, 1999.

BOORMAN, K.N. Dietary constraints on nitrogen retention. In: BUTTERY, P.J.; LINDSAY, D.B. (Eds.) Protein deposition in animals. London: Butterworths, 1981. p.147-166.

BURNHAM, D., GOUS, R.M. Isoleucin requirements of the chicken: requirement for maintenance. British Poultry Science, v.33, n.1, p.59-69, 1992.

CHWALIBOG, A. Factorial estimation of energy requirements for egg production. Poultry Science, v.71, n.3, p.509-515, 1992.

FISHER, C. Protein deposition in poultry. In: BUTTERY, P.J.; LINDSAY, D.B. (Eds.) Protein deposition in animals. London: Butterworths, 1981. p.251-210.

HURWITZ, L.; BORNSTEIN, S. The protein and amino acid requirements of laying hens: suggested models for calculation. Poultry Science, v.52, n.3, p.1124-1134, 1973.

HURWITZ, L.; SKLAN, D.; BARTOV, I. New approaches to the determination of energy and amino acid of chicks. Poultry Science, v.57, n.1, p.197-205, 1978.

LONGO, F.A.; SAKOMURA, N.K.; FIGUEIREDO, A.N. et al. Equações de predição das exigências protéicas para frangos de corte. Revista da Sociedade Brasileira de Zootecnia, v.30, n.5, p.1521-1530, 2001.

MACLEOD, M.G. Energy and nitrogen intake, expenditure and retention at $20^{\circ}$ in growing fowl given diets with a wide range of energy and protein contents. British Journal Nutrition, v.64, n.3, p.625-637, 1990.

MACLEOD, M.G. Fat deposition and heat production as responses to surplus dietary energy in fowls given a wide range of metabolizable energy: protein ration. British Journal Nutrition, v.32, n.5, p.1097-1108, 1991.
NIETO, R.; PRIETO, C.; FERNANDEZ-FÍGARES, I. et al. Effect of dietary protein quality on energy metabolism in growing chickens. British Journal Nutrition, v.74, n.1, p.163-172, 1995.

SANTOMÁ, G. Necessidades protéicas de las gallinas ponedoras. In: DE BLAS, C.; MATEOS, G.G. (Eds.) Nutricion y alimentación de gallinas ponedoras. Madrid: MundiPrensa, 1991. p.71-114.

SAKOMURA, N.K. Exigências nutricionais de energia metabolizável para reprodutoras pesadas, poedeiras semipesadas e leves. Viçosa, MG: Universidade Federal de Viçosa, 1989. 242p. Tese (Doutorado em Zootecnia) - Universidade Federal de Viçosa, 1989.

SAKOMURA, N.K. Exigências nutricionais das aves utilizando o modelo fatorial. In: SIMPÓSIO INTERNACIONAL SOBRE EXIGÊNCIAS NUTRICIONAIS DE AVES E SUÍNOS, 1996, Viçosa, MG. Anais... Viçosa, MG: Universidade Federal de Viçosa, 1996. p.361-388.

SAS INSTITUTE. SAS Guide Statistics. Version 6. 12.ed. Cary: 1996.

SCOTT, M.L.; NESHEIM, M.C.; YOUNG, R.J. Nutrition of the chicken. 3.ed. Ithaca: M.L. Scott, 1982. 562p.

SILVA, R. Equações de predição das exigências das exigências de energia e proteína para matrizes pesadas em crescimento. Jaboticabal: Universidade Estadual Paulista, 1999. 153p. Tese (Doutorado em Zootecnia) - Universidade Estadual Paulista, 1999.

Recebido em: 20/06/01 Aceito em: 28/01/02 